\title{
"Yeah, I know this": Student Experiences in a Blended MicroMasters Program $^{1}$
}

\author{
Joshua Littenberg-Tobias \\ MIT Teaching Systems Lab \\ jltobias@mit.edu
}

\author{
Justin Reich \\ MIT Teaching Systems Lab \\ jreich@mit.edu
}

\section{INTRODUCTION}

Providers of massive open online courses (MOOCs) continue to experiment with new mechanisms for providing transferable course credit and alternative credentials, such as edX's MicroMasters or Coursera's Specializations [1-3]. In some cases, such as Georgia Tech's Masters in Computer Science, the programs are entirely facilitated through MOOCs, and in others the courses count for credit in traditional degree programs [4-5].

In the edX MicroMasters program, students take a series of MOOCs and then a proctored final exam to earn a MicroMasters credential. Students can apply for admissions into accelerated Master's degree programs that accept the MicroMasters certification as credits. Students can complete their programs faster and less expensively by earning credit online, and universities can use the online coursework for "inverted admissions"- accepting students on the basis of demonstrated competence in a domain, as shown by their performance in the MicroMasters, in place of standardized test scores or undergraduate grades.

These developments have the potential to expand access to credentials to underserved populations [6] This mixed-methods studies uses student interviews, survey responses, and MOOC $\log$ data to examine the experience of students participating in an edX MicroMasters in a private university in the Northeastern United States.

\section{METHODS}

\section{A. MicroMasters Program}

We investigated a MicroMasters program where students completed five online courses and a proctored exam to earn a MicroMasters credential. Credential earners were then eligible to apply for a one-semester residential Master's degree program at one of two different universities, which typically required two semesters of classes.

\section{B. Log Data and Surveys}

We analyzed $\log$ data from all students $(\mathrm{N}=116,850)$ who viewed one of the five courses in the program (with twenty total course runs) over a three year period. We identified students who received a MicroMasters credential $(\mathrm{N}=1,010)$ and those who enrolled in the blended graduate degree program $(\mathrm{N}=39)$. We also linked the log data to pre-course survey results, matching $65 \%$ of verified MOOCs students, $90 \%$ of MicroMasters, and $92 \%$ of blended students.

\section{Interviews}

We conducted semi-structured interview with $\mathrm{N}=33$ students in the one-semester blended graduate degree program and $\mathrm{N}=18$ students in the comparable full-year residential graduate degree program. Codes were generated using a constant comparative approach [6-7] and interviews were coded by at least two independent raters (inter-rater reliability: $\kappa=0.70)$.

\section{FINDINGS}

In this analysis we focused on three research questions: 1) What are the educational and work backgrounds of students in the MicroMasters and blended program? 2) What are their motivations for participating? 3) How do students experience MOOC-based blended graduate programs? We are currently collecting and analyzing additional data about student experiences in the on-campus portion of the blended graduate program and will include those findings in future papers.

\section{A. Educational and Work Backgrounds}

The modal student who completed the MicroMasters was a mid-career professional currently working in the developed world. Of the 1,010 students who earned a MicroMasters in this program, $87 \%$ were employed. $41 \%$ of students were from North America, 10\% from South America, 22\% from Europe, $21 \%$ from Asia, $4 \%$ from Africa and $2 \%$ from Oceania. Only $40 \%$ were from countries categorized by the UN as a developing nation. Nearly all completers had undergraduate degrees (96\%), and many already had graduate degrees $(51 \%)$. The average age of learners when they completed the MicroMasters was $34.8(\mathrm{SD}=8.0)$.

Students who enrolled in the blended graduate degree program were somewhat younger than the average MicroMasters student $(31.9, \mathrm{SD}=5.5)$, but were older than students in the residential graduate degree program $(28.8, \mathrm{SD}$ $=3.2$ ). Blended students had, on average, 9.1 years of work experience $(\mathrm{SD}=5.7)$ compared to students in the residential program who on average 6.4 years of work experience $(\mathrm{SD}=$ 2.7). The majority of students in the blended program, $59 \%$, had a graduate degree. For most blended students, the blendedgraduate program they considered. Only $6 \%$ of blended students said they considered applying to other graduate programs compared to $71 \%$ of residential students.

Blended students also had different career aspirations than students in the residential graduate program. Of the students we interviewed, $71 \%$ of blended students said they planned or

\footnotetext{
${ }^{1}$ Presented at the 2018 HybridEd Workshop in Cambridge, MA
} 
could go back to their previous position compared to only $13 \%$ of residential students. Many students said their companies were willing to hold their position and give them leave for six months in order to complete the program.

\section{B. Motivations for Participating in the MicroMasters Program}

Learners enrolled in MicroMasters courses because they believed they would learn skills that would be valuable in their current job. On their pre-course surveys, $89 \%$ of students who completed the MicroMasters responded that "advancing their career" was a "very important" reason for enrolling in a course. Once in the courses, students found that the content could be directly applied to their jobs. Of the students we interviewed, $84 \%$ said they found that the course helped them in their job performance, and many shared examples of how they were able to apply what they learned in their work.

"I used all my learning from [the courses], to challenge my supplier back saying that, "You can do this whole production as per the schedule, and this is the planning you should do. Let me know where you feel you that have a challenge." And then, they were little surprised also that how I can do this? I said, "Yeah, I know this."

Earning a certificate was also an important motivation for many students with $74 \%$ of students saying it was an important reason for them to complete the course. In interviews, many students described the opportunity to earn a MicroMasters as a motivating factor.

I think at the time...there was just one class. I say, "Okay, I'll take this one." And they say, "Okay, if you're not paying, I'm not going to do it."...I went and paid. And then I found out there's you can actually do five course and then get a credential, that's pretty cool. "Okay, I'll do everything then."

Many students reported viewing the MicroMasters as a gateway to earning a full Master's degree. $49 \%$ of students who complete the MicroMasters said it was "very likely" they would apply to the residential graduate program.

They're looking for the inverted admissions through the MicroMasters to the proper degree program. And then it became like, okay. So this is more a decision point, this looks like this course is turning towards a degree."

However, some students expressed uncertainty as to how much employers might independently value the MicroMasters. In pre-course surveys, only $21 \%$ said it was very likely they would use the MicroMasters to seek a promotion and only 34\% said it was very likely they would use it to secure a new job.

\section{Student Experiences in Alternative Credential Programs}

Students who completed the MicroMasters spent an average of 167 hours on the edX platform over 289 days (a little more than 35 minutes a day) - an impressive number considering many were also managing full time jobs. In interviews, students described juggling their schedules in order to make time for completing the course.

"That was very, very tough. I work a lot. I work sometimes I would say 60 hours a week....And I was doing the online courses between 1:00 and 3:00 AM in the morning so that was very tiring and a lot of tea to keep going like that."

Students working independently in MOOCs lacked many of structures, such as designated class times and in-person interactions, that assist students in in-person courses to stay focused on learning. One way students promoted greater selfregulated strategies was through their goal-orientation [9]. In interviews, students described their reasons for completing the alternative credential in terms of "mastery" goal orientation (focus on new skills and knowledge) rather than a "performance" goal orientation (focus on grades).

\section{It's gonna sound geeky but just learning about the analytical aspects of [the subject] really interested me. And just all this knowledge that I kind of knew tangentially from my work in operations but once you start getting into the basics of it, this is why this is the way that is, just all that that I didn't know....And that got just got my juices flowing for the knowledge.}

The community forums were also an important source of support for students who completed the MicroMasters program. $77 \%$ of students who completed the MicroMasters posted at least once in the forums and the average student 20.5 times over the course of the program.

\section{DISCUSSION AND LIMITATIONS}

Alternative credentials have the potential to create new pathways for workers to "skill up" in critical areas, but often face challenges in terms of gaining acceptance and expanding access to underserved groups [6] This study found that the students who completed a MicroMasters were mostly educated mid-career professionals working in developed countries. These students were largely motivated by the opportunity to advance their skills, their interest in the content area, and passion for lifelong learning.

For residential instructors, the findings of this study suggest that MOOC-based blended program can be an effective way of recruiting highly-qualified non-traditional applicants to residential programs. Compared to standardized test scores or undergraduate grades, performance in a MOOC more directly measures the competencies that would lead to success in a residential graduate program. Through MOOCs, students demonstrate mastery of course content, commitment to learning (by working at night and on weekends), and passion for the subject through posting on the forums. Another benefit is that admitting students through MOOCs is that it "locks" qualified students into a specific graduate program while they are still at the early stage of considering a graduate degree and may encourage applicants to apply who otherwise were not considering applying to a graduate program.

One limitation of this study is that we have not finished collecting data on student experiences on campus. We are currently interviewing and surveying students about their residential experience including self-perceived academic preparation, sense of belonging, and interactions with classmate and faculty. We are also collecting data about student grades and career outcomes. Once we integrate these findings into the analysis we will have a better understanding of how successful 
a blended approach is at providing meaningful learning experiences for students.

\section{REFERENCES}

[1] Caudill, J. (2017). The Emerging Formalization of MOOC Coursework: Rise of the MicroMasters. Proceedings of EdMedia 2017 (pp. Johnston, J.). Washington, DC: Association for the Advancement of Computing in Education (AACE).

[2] Hollands, F. (2017). Costs and Benefits of Alternative Credentials Baseline Report. New York: Teachers College, Columbia University.

[3] Wulf, J., Blohm, I., \& Brenner, W. (2014). Massive Open Online Courses. Buisness \& Information Systems Engineering, 2, 111-114.

[4] Ingolfsdottir, K. (2016). Winds of change in higher educaton. Trends in Pharmacological Science, 37(12), 990-992.

[5] Goodman, J., Melkers, J., \& Pallais, A. (2018). An elite grad-school degree goes online: Can Georgia Tech's virtual master's increase access to education? EducationNext, $18(3)$.

[6] Barabas, C., \& Schmidt, P. (2016). Transforming chaos into clarity: The promises and challenges of digtial credentials. Washington, DC: The Roosevelt Institue.

[7] Boeije, H. (2002). A purposeful approach to the constant comparative approach in the analysis of qualitative interviews. Quality and Quantity, 36, 391-409.

[8] Glaser, B., \& Strauss, A. (1967). The Discovery of Grounded Theory: Strategies for Qualitative Research. Chicago: Aldine.

[9] Pintrich, P. (2000). The role of goal orientation in selfregulated. In M. Boakaerts, P. R. Pintrich, \& M. Zeidner, Handbook of self-regulation (pp. 451-502). San Diego, CA: Academic Press. 